\title{
Grey Wolf Optimizer for Detecting Aging of Power Cables
}

\author{
Loai Nasrat \\ Department of Electrical Eng. Dept., Faculty \\ of Engineering, Aswan University, 81542 \\ Aswan, Egypt \\ loaisaad@yahoo.com
}

\author{
Mervat Hassan \\ Ore Evaluation Lab, Minerals \\ Technology. \\ Dept. Central Metallurgical R \& D \\ Institute Cairo, Egypt
}

\author{
Gehad Abdelgawad \\ Maintenance Engineer At Al Marwa Co. \\ Qena, Egypt \\ Email: Gehadengineer@yahoo.com
}

\begin{abstract}
Polyvinyl chloride (PVC) is widely used in high and medium voltage cables insulation because of its low dielectric losses and its ability to improve cables properties in high temperatures. This paper aims to improve PVC electrical properties (dielectric strength) for high voltage and medium voltage cables in respect of mechanical characteristics by adding inorganic filler. Blends of PVC with inorganic filler : Silica (Sio2) were prepared with $10 \%, 20 \%, 30 \%$ and $40 \%$ by weight percentages concentration. The dielectric strength of the blends was tested in several thermal conditions such as $(0,25,65$ and 125C). Also dielectric strength of blends was tested after being immersed in water for 24 hours, 7 days and 10 day. Tensile strength was applied to investigate the mechanical properties of PVC after adding silica filler with $10 \%, 20 \%, 30 \%$ and $40 \%$ concentration percentages. Soft program (Curve fitting) is used to select the most proper equation between dielectric strength values under each condition and different percentages of Silica filler also between tensile strength and the same percentages of Silica filler. Grey Wolf Optimizer (GWO) was applied to find the best suitable percentages of Silica filler to obtain the best optimal values of dielectric strength and tensile strength .
\end{abstract}

Keywords - PVC; Silica; Dielectric strength; Tensile strength; GWO.

\section{I .INTRODUCTION}

The use of power cable is assumed to be started back in 1880 , with the start of incandescent lighting. The growth rate of urban electrification was too high to accommodate the number and size of the feeders required for distribution using overhead lines. The overhead line system was not only considered technically and aesthetically inadequate, but also it was assumed to pose safety hazards. For these reasons, underground electrification technology was introduced by the early 1890's [1].

High voltage cables are used when underground transmission is required. These cables are laid in ducts or may be buried in the ground. Unlike in overhead lines, air does not form part of the insulation, and the conductor must be completely insulated. Thus cables are much more costly than overhead lines. Also, unlike for overhead lines where tapping can easily give, cables must be connected through cable boxes which provide the necessary insulation for the joint [2].
Cables are an integral part of the power transmission and distribution network. As the voltage level increases, amount of insulation used in the cable increases. Therefore a need arises for a material with better insulation characteristics to be used in cables. The dielectric strength of cable insulation depends on many factors such as the existence of filler material in the insulation [3].

Polyvinyl chloride (PVC) is used as an insulating material in power cable construction. This is due to its good features such as easy processing, low cost, excellent mechanical properties, having greater rigidity than other general-purpose thermoplastic materials and good insulation performance

PVC works safely at $75^{\circ} \mathrm{C}$ in wet weather and at $90{ }^{\circ} \mathrm{C}$ in dry weather, Under overload or short circuit conditions, PVCinsulated cables are exposed to thermal stress (thermal ageing). This stress leads to gradual degradation of the initial product characteristics. The degradation causes irrevocable changes in the insulation properties, which rapidly reduce their lifetime. Therefore, the development of insulated cable is required to ensure long life under high temperatures[4].

Nano composites have better thermal stability with surface treated silica(Sio2) and also have lower weight loss rate with better flame retardant ability. The surface treatment of nanosilica improves the compatibility between polymer and inorganic fillers by showing higher elongation.

The improved compatibility between polymer and treated silica provide better tensile strength[5]

Optimization is the act of obtaining the best result under given circumstances. Optimization can be defined as the process of obtaining the conditions that give the maximum or minimum value of a function. Thus without loss of generality, optimization can be taken to mean minimization since the maximum of a function can be found by seeking the minimum of the negative of the same function [6].

Grey Wolf Optimizer (GWO) Mirjalili for the first time simulated the mathematical model of the behavior of the Grey Wolf Optimizer (GWO). GWO is a meta-heuristics natural inspired method belongs to swarm intelligence (SI) algorithms. SI is "The emergent collective intelligence of groups of simple agents". The inspirations of SI techniques originate mostly from natural colonies, flock, herds and schools. It imitates the grey wolves behavior in attacking and hunting a prey. Grey wolves prefer living in packs with a 
robust social dominant hierarchy. The first three fittest wolves are considered as alpha, beta and delta who guide other remaining wolves $(\omega)$ toward promising areas of the search space. For an optimization problem, the best solution is represented by alpha wolves, the second and third best solutions are beta and delta wolves while omega wolves provide all the other solutions [7-8]

\section{II.EXPERIMENTAL PROCEDURE}

\section{A. Samples preparation}

The preparation of PVC depends on different parameters such as the ratio of PVC, types and concentrations of filler that affect on properties of the base material and final product. Samples have been prepared in the laboratory of the polymers and pigments department National Research Center (NRC). Polymer composite was prepared by mixing different ratios of Silica filler $(0,10,20,30$ and 40 wt. \%). The samples preparation were operated at the room temperature $\left(25^{\circ} \mathrm{C} \pm 1\right)$, until curing occurred. The composition of the samples is given in table 1

Table.1.Composition of samples with different concentrations of Silica (Sio2) filler.

\begin{tabular}{|c|c|}
\hline $\begin{array}{l}\text { Polyvinyl chloride } \\
\text { by Weight }(\%)\end{array}$ & $\begin{array}{l}\text { Silica filler } \\
\text { Percentage(\%) }\end{array}$ \\
\hline 100 & 0 \\
\hline 90 & 10 \\
\hline 80 & 20 \\
\hline 70 & 30 \\
\hline 60 & 40 \\
\hline
\end{tabular}

\section{B. Dielectric Breakdown Strength Test.}

Dielectric strength of an insulating material is the maximum electric field strength that it can withstand intrinsically without breaking down, without experiencing failure of its insulating properties. It is expressed in voltage gradient items, such as voltage per thickness $(\mathrm{kV} / \mathrm{mm})$. It is one of the major electrical properties for insulation.

The failure is characterized by an excessive flow of current (arc) and by partial destruction of the material.

Dielectric strength is measured through the thickness of the specimen (which is equal to $1 \mathrm{~mm}$ ), and is expressed in volts per unit of thickness. Sets of blends have been prepared and tested using A.C voltage according to IEC 60243 in different temperatures range. Samples are in the form of disc with diameter $5 \mathrm{~cm}$ and thickness $1 \mathrm{~mm}$. For each test, the average result of 10 samples has been taken to minimize the error .

Fig.1 shows the circuit used for dielectric break down strength test.

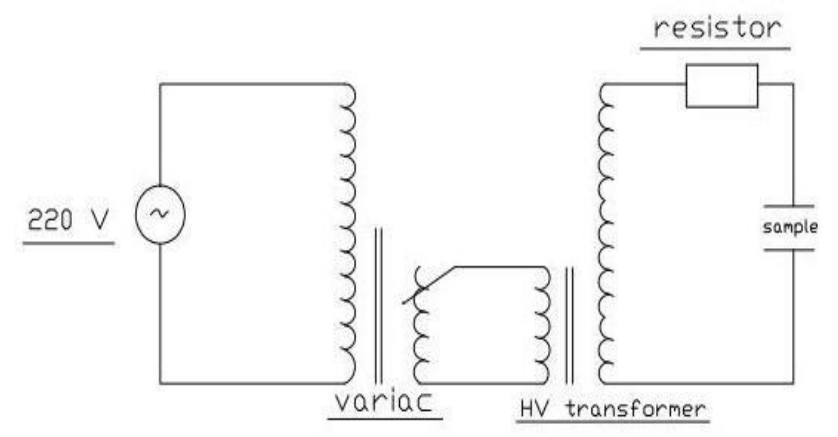

Fig 1:- Schematic diagram for the dielectric strength testing circuit.

By using curve fitting methods, The relation between different temperatures and the inorganic filler percentage was obtained.

\section{Mechanical Test.}

Mechanical tests such as tensile strength has been done to evaluate the mechanical performance of composite insulators according to ASTM D638 for tensile strength, three identical specimens have been tested.

\section{III .RESULTS AND DISCUSSION}

\section{A. Electrical Measurements}

The dielectric strength for PVC has been studied with different filler $\mathrm{wt} \%$ in different temperatures :

$0^{\circ} \mathrm{C}$ (to simulate the climate of snowy regions), $25^{\circ} \mathrm{C}$ (to simulate room temperature), $65^{\circ} \mathrm{C}$ and $125^{\circ} \mathrm{C}$ (to simulate maximum temperature loading of the cables). Fig. 2 shows the comparison of breakdown strength for new samples with different filler wt $\%$ and the virgin sample without any additives. It can be interpreted that the dielectric strength of PVC was improved by adding Sio2 filler until definite value then the dielectric strength decreased.

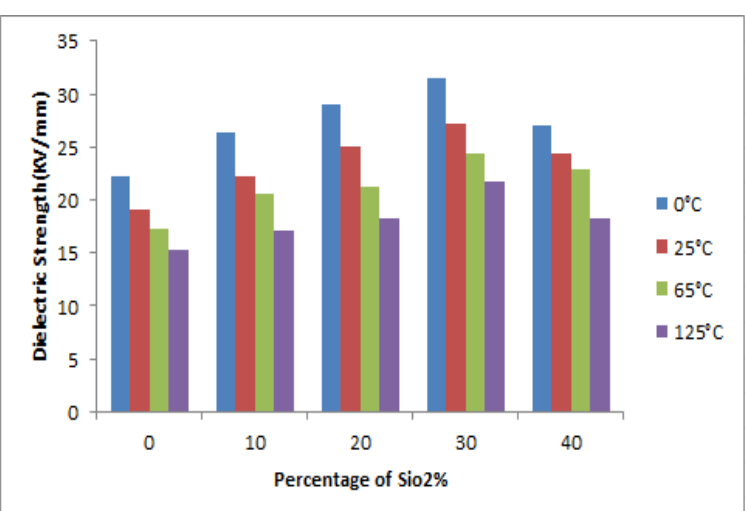

Fig 2:- Dielectric strength $(\mathrm{KV} / \mathrm{mm})$ for PVC with different Silica percentages at various temperatures. 
International Journal of Applied Energy Systems, Vol. 2, No. 2, July 2020 ISSN: 2636 - 3712 (Printed Version) ISSN: 2636 - 3720 (Online Version) Special Issue: ICEE-2019

-For $0^{\circ} \mathrm{C}$ the dielectric strength of PVC with Sio2 (10, 20 and $30 \mathrm{wt} \%)$ was improved by $(18.5 \%, 30.75 \%$ and 42 ) to reach $(26.33,29.04$ and $31.56 \mathrm{kV} / \mathrm{mm})$ respectively except in $40 \%$ sample the dielectric strength decreases

-For $25^{\circ} \mathrm{C}$ the dielectric strength of PVC with Sio2 (10, 20 and 30 wt \%) was improved by $(16 \%, 30.77 \%$ and $41.6 \%)$ to reach $(22.25,25.0,27.11 \mathrm{kV} / \mathrm{mm})$ respectively except in $40 \%$ sample the dielectric strength decreases.

-For $65^{\circ} \mathrm{C}$ the dielectric strength of PVC with Sio2 (10, 20 and $30 \mathrm{wt} \%)$ was improved by $(18 \%, 22 \%$ and 40.7$)$ to reach $(20.50,21.22$ and $24.39 \mathrm{kV} / \mathrm{mm}$ ) respectively except in $40 \%$ sample the dielectric strength decreases.

-For $125^{\circ} \mathrm{C}$ the dielectric strength of PVC with Sio2 (10, 20 and $30 \mathrm{wt} \%)$ was improved by $(18 \%, 22 \%$ and 40.7$)$ to reach $(17.16,18.27,21.78 \mathrm{kV} / \mathrm{mm})$ respectively except in $40 \%$ sample the dielectric strength decreases.

It can be interpreted from fig. 2 that the breakdown strength of PVC insulation is reversely proportional to temperatures, where the dielectric strength has maximum value at $0 \mathrm{C}$, but it had minimum value at $125 \mathrm{C}$.

Furthermore, the dielectric strength test was carried out after the blends were immersed in water for different times:

(24 hours , 7 days and 10 days ) Fig.3 shows that, PVC was improved by adding Sio 2 filler until definite value then the dielectric strength decreased.



Fig3:- Dielectric strength $(\mathrm{KV} / \mathrm{mm})$ for $\mathrm{PVC}$ with different Silica percentages after immersion samples in water for various times

- As for 24 hours, the dielectric strength of PVC with Sio2 $(10,20$ and $30 \mathrm{wt} \%)$ was increased to reach $(17.16,18.27$ and $21,78 \mathrm{kV} / \mathrm{mm})$ respectively except at $(40 \% \mathrm{Sio} 2)$ it decreases to reach $18,31 \mathrm{kV} / \mathrm{mm}$.

- As for 7 days, the dielectric strength of PVC with Sio2 $(10,20$ and $30 \mathrm{wt} \%)$ was increased to reach $(22.11,24.89$ and $25.62 \mathrm{kV} / \mathrm{mm})$ respectively except at $(40 \% \mathrm{Sio} 2)$ it decreases to reach $22.85 \mathrm{kV} / \mathrm{mm}$.

- As for 10 days, the dielectric strength of PVC with Sio2 $(10,20$ and $30 \mathrm{wt} \%)$ was increased to reach $(20.77$ and $24.07 \mathrm{kV} / \mathrm{mm})$ respectively except at $(30 \% \mathrm{Sio} 2)$ it decreases to reach $23.86 \mathrm{kV} / \mathrm{mm}$.

It can be interpreted from fig.3 that the breakdown strength of PVC insulation is reversely proportional to time immersion, where the dielectric strength has maximum value at 24 hours, but it had minimum value at 10 days.

\section{A. Soft Program (MATLAB) Results}

Applying Curve fitting (regression analysis) using Matlab program, the best curve fitting for the obtained results from the test are shown in Fig (4) for $0^{\circ} \mathrm{C}$ condition. Representing the data by a $4^{\text {th }}$ degree polynomial equation to minimize the error as possible we get.

The equations of curve fitting results for the dielectric strength of blends at $0^{\circ} \mathrm{C}, 25^{\circ} \mathrm{C}, 65^{\circ} \mathrm{C}$ and $125^{\circ} \mathrm{C}$ as follows:

1- At $0^{\circ} \mathrm{C}$ is :

$\mathrm{Y}=-3.4 \mathrm{e}-5 * \mathrm{X} 4+0.0022 * \mathrm{X} 3-0.05 * \mathrm{X} 2+0.73 * \mathrm{X}+22$

(1)

2- At $25{ }^{\circ} \mathrm{C}$ is:

$\mathrm{Y}=-1.5 \mathrm{e}-5 * \mathrm{X} 4+0.00087 * \mathrm{X} 3-0.017 * \mathrm{X} 2+0.41 * \mathrm{X}+19$

(2)

3-At $65{ }^{\circ} \mathrm{C}$ is:

$\mathrm{Y}=-5 \mathrm{e}-5 * \mathrm{X} 4+0.0038 * \mathrm{X} 3-0.092 * \mathrm{X} 2+0.91 * \mathrm{X}+17$ (3)

4-At $125{ }^{\circ} \mathrm{C}$ is:

$\mathrm{Y}=-5.2 \mathrm{e}-5 * \mathrm{X} 4+0.0037 * \mathrm{X} 3-0.077 * \mathrm{X} 2+0.64 * \mathrm{X}+15$

(4)

Where $\mathrm{Y}$ parameter is the dielectric strength value $(\mathrm{KV} / \mathrm{mm})$ at all different conditions, $\mathrm{X}$ is the percentage of concentration of Silica filler in the samples.

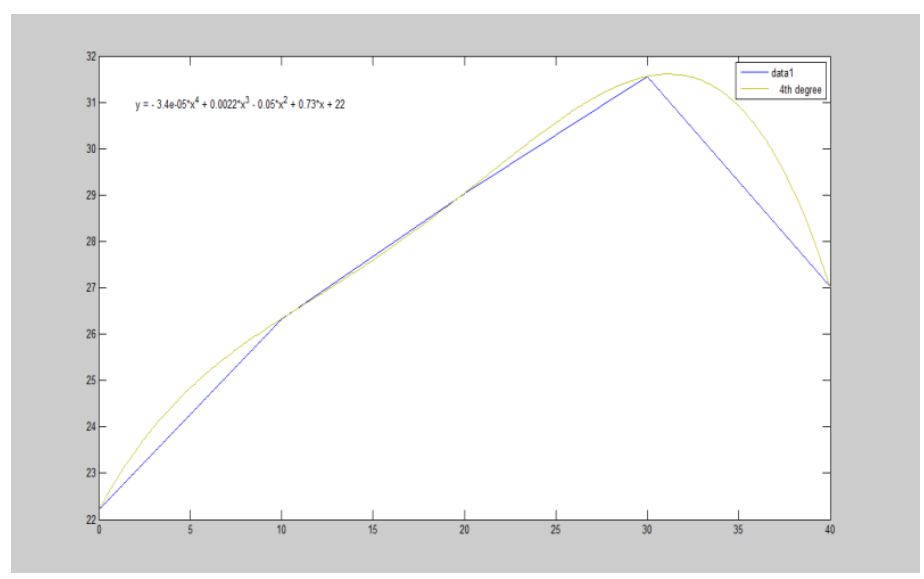


Fig 4:- Dielectric strength of PVC/Silica at $0^{\circ} \mathrm{C}$.

GWO was applied to find the best percentage of Silica filler by inserting the negative of the equations (1-4) in the code of the program to obtain the best optimal value of dielectric strength in each condition.

After applying GWO at $0^{\circ} \mathrm{C}$ condition by inserting the negative of equation (1), the best solution obtained by GWO is $30 \%$ of Silica filler to obtain the best optimal value of dielectric strength as evident in Fig (5).

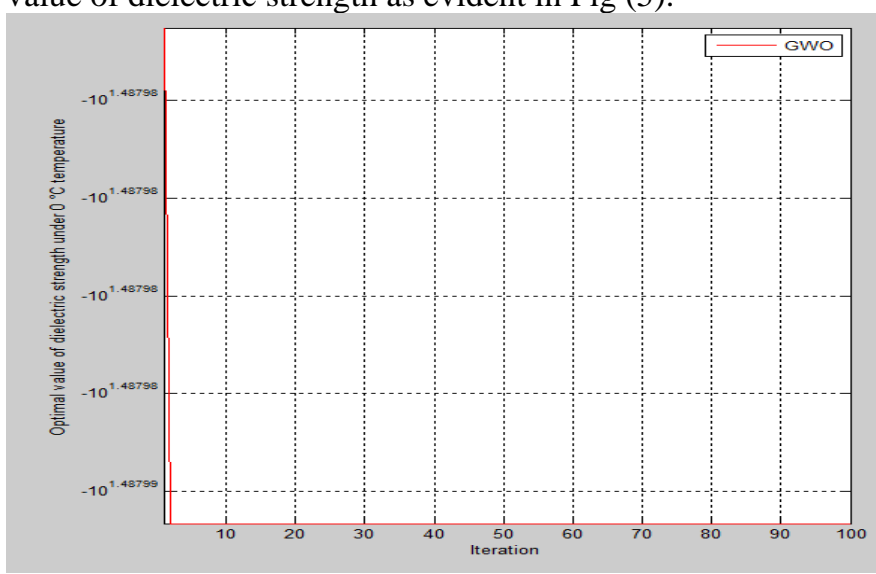

Fig 5:- The optimal value of dielectric strength at $0^{\circ} \mathrm{C}$.

At $25^{\circ} \mathrm{C}$ by inserting the negative of equation (2), the best solution of Silica filler percentage obtained by GWO is $32.5398 \%$ to obtain the best optimal value of dielectric strength.

At $65^{\circ} \mathrm{C}$ by inserting the negative of equation (3), the best solution of Silica filler percentage obtained by GWO is $33.1756 \%$ to obtain the best optimal value of dielectric strength.

At $125^{\circ} \mathrm{C}$ by inserting the negative of equation (4), the best solution of Silica filler percentage obtained by GWO is $34.9802 \%$ to obtain the best optimal value of dielectric strength.

Note: The optimal value of dielectric strength is negative in Fig (5) because of inserting a negative sign to equation (1).

The equations of curve fitting results for the dielectric strength of samples had been immersed for 24 hours ,7 days and 10 days as follows:

5-For $24 \mathrm{~h}$ is:

$\mathrm{Y}=-1.7 \mathrm{e}-5 * \mathrm{X} 4+0.0009 * \mathrm{X} 3-0.017 * \mathrm{X} 2+0.41 * \mathrm{X}+19$

(5)

6-For 7 days is:
$\mathrm{Y}=1.3 \mathrm{e}-6 * \mathrm{X} 4-0.00037 * \mathrm{X} 3+0.0086 * \mathrm{X} 2+0.26 * \mathrm{X}+19$

(6)

7-For 10 days is:

$\mathrm{Y}=2.6 \mathrm{e}-5 * \mathrm{X} 4-0.0023 * \mathrm{X} 3+0.054 * \mathrm{X} 2-0.092 * \mathrm{X}+18$

(7)

Where $\mathrm{Y}$ parameter is the dielectric strength value $(\mathrm{kV} / \mathrm{mm})$ at all different conditions, $\mathrm{X}$ is the percentage of concentration of Silica filler in the samples.

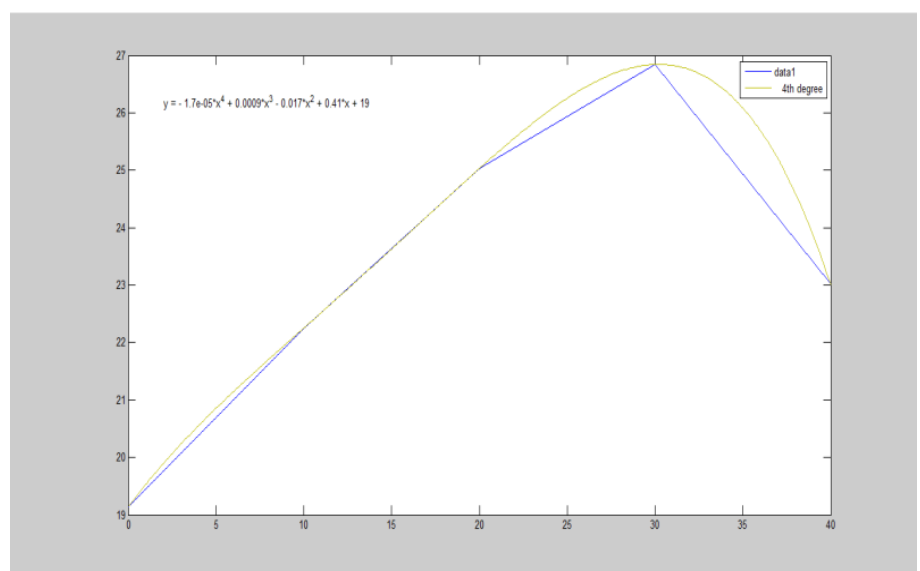

Fig 6:- Dielectric strength of PVC/Silica after immersion for $24 \mathrm{hrs}$.

After applying GWO under wet condition by inserting the negative of equation (5), the best solution obtained by GWO is $30 \%$ of Silica filler to obtain the best optimal value of dielectric strength as evident in Fig (7).

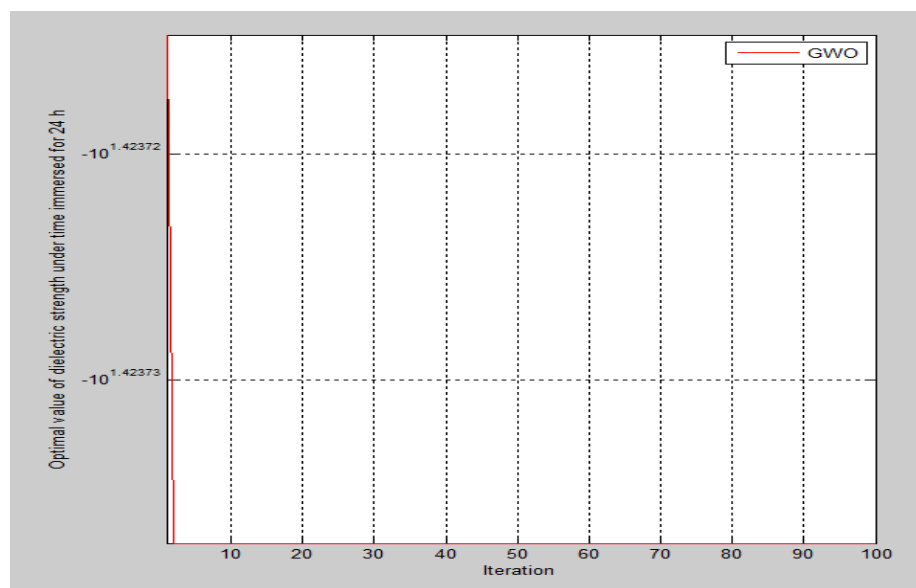

Fig 7:- Dielectric strength of PVC/Silica after immersion for 24 hours.

For 7 days by inserting the negative of equation (6), the best solution of Silica filler percentage obtained by GWO is $30 \%$ to obtain the best optimal value of dielectric strength. 
For 10 days by inserting the negative of equation (7), the best solution of Silica filler percentage obtained by GWO is $30 \%$ to obtain the best optimal value of dielectric strength.

\section{Mechanical Measurements}

Tensile strength tests (TS) are carried out in order to illustrate the ability of PVC filled with different percentages of Silica filler to withstand the mechanical forces.

\section{Tensile strength test}

It can be defined as the maximum tensile sustained by the material being tested to its breaking point.

Tensile strength $=\mathrm{F} / \mathrm{A}$.

It is measured in units of force $(\mathrm{F})$ divided by units of $\operatorname{area}(\mathrm{A})$.

The tensile strength of PVC filled with $0 \%, 10 \%, 20 \%$, $30 \%$ and $40 \%$ of Silica filler has been tested.

Fig (8) shows the tensile strength of PVC with Silica filler.

From Fig (8) it's obviously seen that the tensile strength increased gradually with increasing the percentage of Silica filler until $20 \%$ then the tensile strength decreased.

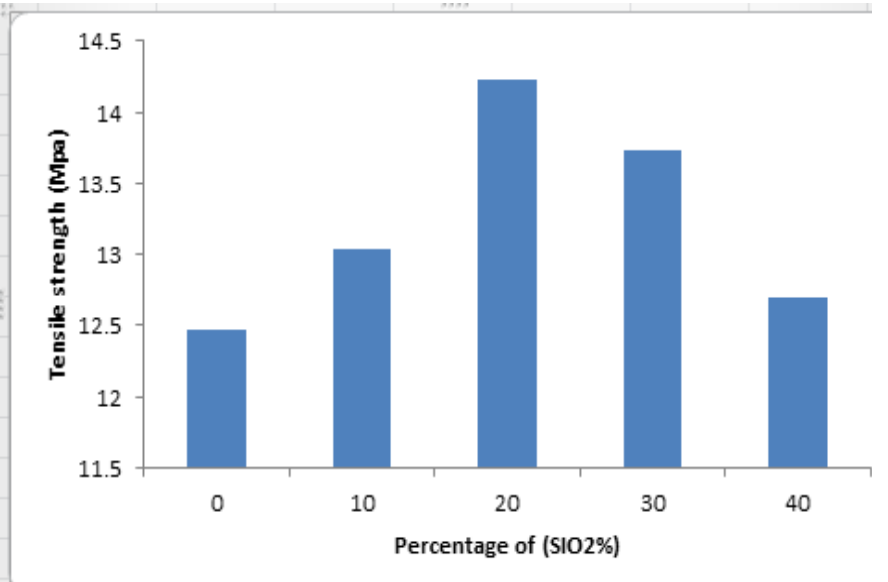

Fig 8:- Tensile strength (MPa) of PVC/Silica

Applying Curve fitting (regression analysis) using Matlab program, the best curve fitting for the obtained results from the test are shown in Fig (9).

The equation of curve fitting results for the tensile strength of blends is:

$\mathrm{Y}=1.5 \mathrm{e}-5 * \mathrm{X} 4-0.0013 * \mathrm{X} 3+0.031 * \mathrm{X} 2-0.14 * \mathrm{X}+12$

(8)

Where Y parameter is the tensile strength $(\mathrm{MPa}), \mathrm{X}$ is the percentage of concentration of Silica in the samples.

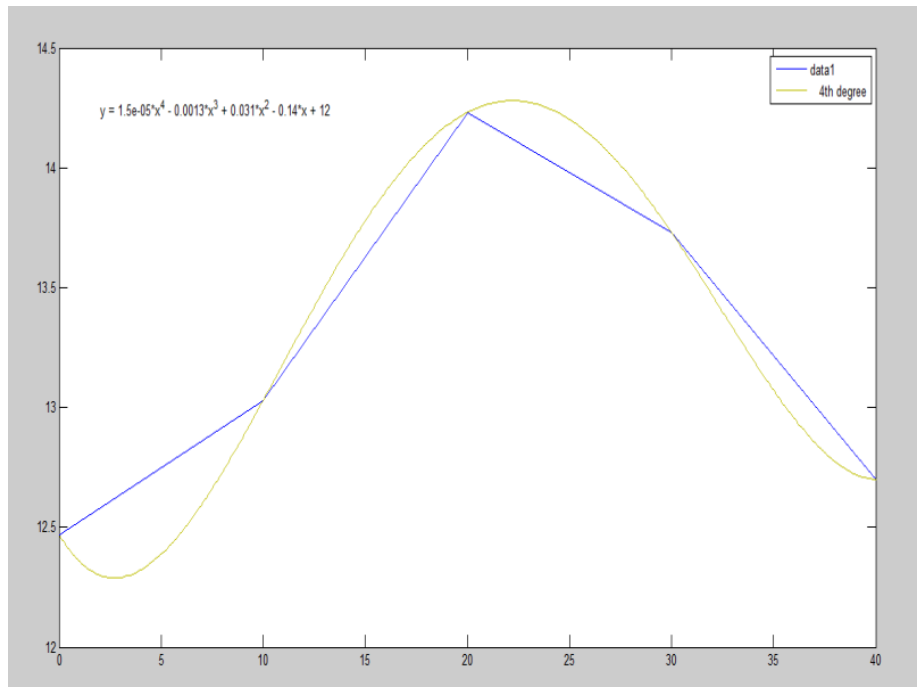

Fig 9:- Tensile strength (MPa) of PVC/Silica

GWO was applied to find the best percentage of Silica filler by inserting the negative of the equation (8) in the code of the program to obtain the best optimal value of tensile strength.

After applying GWO by inserting the negative of equation (8), the best solution obtained by GWO is $20.9 \%$ of Silica filler to obtain the best optimal value of tensile strength as evident in Fig (10)

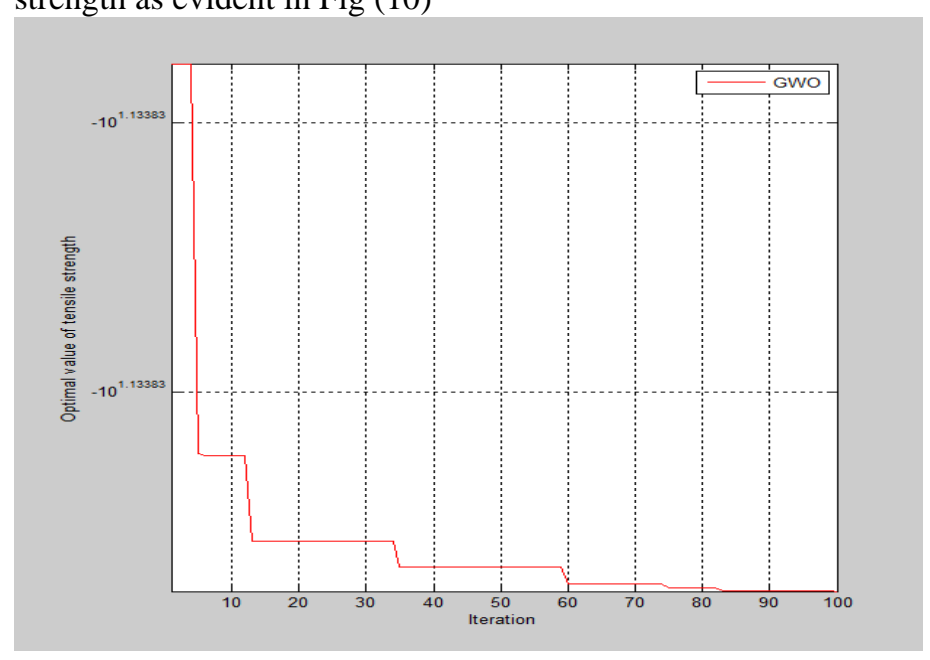

Fig 10:- The optimal value of tensile strength.

Note: The optimal value of tensile strength is negative because of inserting a negative sign to equation (8).

From this study both dielectric and tensile strengths increased with increasing the Silica filler percentage until definite value then they decreased. This is due to the saturation that happened in the lattice of PVC and the more addition of Silica filler to PVC made the composites brittle so both dielectric and tensile strength decreased.

\section{IV .CONCLUSION}


The addition of Silica filler had resulted some improvement in the electrical and mechanical properties of PVC.

GWO gives definite indications of filler percentage to obtain the optimal values of dielectric strength and tensile strength.

1-For low temperatures at $\left(0^{\circ} \mathrm{C}\right)$, the PVC dielectric strength was improved by the increase of Silica concentrations by almost $42 \%$ for $30 \mathrm{wt} \%$, except in $40 \% \mathrm{wt}$ it decreased.

2-Under wet condition, the PVC dielectric strength of samples were immersed for $24 \mathrm{hrs}$ was improved by the increase of Silica concentrations by almost $42.3 \%$ for $30 \mathrm{wt} \%$, except in $40 \% \mathrm{wt}$ it decreased.

3- It can be concluded that, the suitable percentages of Silica filler can be added to PVC which determined by applying GWO are:

$>30 \%$ of Silica filler to obtain the best optimal value of dielectric strength $30.76 \mathrm{kV} / \mathrm{mm}$ at $0^{\circ} \mathrm{C}$.

$>30 \%$ of silica filler to obtain the best optimal value of dielectric strength $26.53 \mathrm{kV} / \mathrm{mm}$ under wet condition for $24 \mathrm{~h}$.

4-The best solution obtained by GWO is $20.9 \%$ of Silica filler to obtain the best optimal value of tensile strength.

\section{ACKNOWLEDGMENTS}

The authors would like to thank the staff of High Voltage Laboratory, Electrical Engineering Dept. Aswan University and National Research Center, Polymers and Pigments Dept.; where most of the samples preparation and experimental work were carried out.

\section{REFERENCES}

[1]-W. A. Thue, adapted from class notes for "Power Cable Engineering Clinic" University of Wisconsin -- Madison, 1997.

[2]-J Rohan Lucas "High voltage engineering" ,Second edition Book, Sir Lanka, 2001.

[3]-D.Edison,R.Vijayaraj,U.Satheeshwaran,"Experimental Investigation on Electrical and Mechanical Characteristics of PVC Cable Insulation with Silica Nano filler", Applied Mechanics and Materials, Vol 749, pp 159-163, 2015.

[4]-M.M.Habashy,A.M.Abdelhady,R.A.Elsad " Performance of $\mathrm{PVC} / \mathrm{SiO} 2$ nanocomposites under thermal ageing",vol 9,issues 3,2019

[5]-P.Sugumaran ," Diagnosis on Mechanical and Electrical Properties of Cable Insulation PVC with Nanofiller " ,IEEE 1st International Conference on Condition Assessment Techniques in Electrical Systems,Kalkota,india,2013.
[6]-S. S. Rao, "Engineering Optimization Theory and Practice 4th Edition", Book, Canada, 2009.

[7]-S. Mirjalili, S. M. Mirjalili, and A. Lewis, "Grey Wolf Optimizer", Advances in Engineering Software, Volume: 69, PP. 46-61, 2014.

[8]-A. Agarwal, A. Chandra, S. Srivastava and R. K Singh, "Grey Wolf Optimizer: A New Strategy to Invert Geophysical Data Sets", Geophysical Prospecting, Volume: 66, Issue: 6, 2018. 